\title{
A docência no sistema modular de ensino da rede pública do Pará e a biografia do padre Josimo Moraes Tavares: perspectivas teórico-práticas para a educação histórica
}

\author{
The Teaching in the Modular System of \\ Teaching of the Public Network of Pará and \\ the Biography of Priest Josimo Moraes Tavares: \\ Theoretical-Practical Perspectives for Historical Education
}

Moisés Pereira Silva* Jôyara Maria Silva de Oliveira ${ }^{\star *}$

\section{RESUMO}

Além de coordenador da Comissão Pastoral da Terra (CPT), o padre Josimo foi um intelectual que, sobretudo utilizando a poesia e o teatro, problematizou os dramas do trabalhador do campo, especialmente da microrregião conhecida como Bico do Papagaio, à época extremo norte de Goiás, parte do Araguaia-Tocantins, atualmente estado do Tocantins. O escopo dessa discussão é pensar a memória da atuação de Josimo nos conflitos sociais rurais e conjecturar, na perspectiva da educação histórica, o que os movimentos sociais no campo e o trabalho dos agentes engajados podem ensinar a quem se ocupa do ensino e da aprendizagem da história enquanto disciplina, ministrada em um contexto es-

\section{Abstract}

Priest Josimo, as well as coordinator of the Pastoral Land Commission (CPT) was an intellectual who, especially from poetry and theater, problematized the dramas of the rural worker, especially in the microregion known as Bico do Papagaio (Parrot's Beak), in the far north of Goiás, part of Araguaia-Tocantins, presently Tocantins state. The scope of this discussion is to think about the memory of Josimo's role in rural social conflicts and to conjecture, from the perspective of historical education, what social movements in rural areas and the work of engaged agents can teach to those who teach and learn about history as a discipline, taught in a specific context, that of Araguaia-Tocantins, in the Modular

\footnotetext{
* Universidade Federal do Tocantins (UFT), Palmas, TO, Brasil. mosico100@gmail.com ** Universidade Federal do Sul e Sudeste do Pará (Unifesspa), Marabá, PA, Brasil. joyaraoliveira@ gmail.com
} 
pecífico, o do Araguaia-Tocantins, no Sistema Modular de Ensino da Rede pública estadual de Educação paraense.

Palavras-chave: Josimo (padre); engajamento; educação histórica.
Teaching System of the public education network of Pará.

Keywords: Josimo (priest); engagement; historical education.

Este é um texto que amalgama pesquisa acadêmica e experiência docente, esta última também tomada como objeto de estudo. Nesse sentido, o lugar de fala dos autores, que reflete seu métier, é o de professores da rede pública estadual do Pará que, desde 2012, atuam no Sistema de Organização Modular de Ensino (SOME) trabalhando em assentamentos rurais do sudeste paraense, área de conflito agrário e, ao mesmo tempo, de trabalho escravo. É nesse contexto que nascem muitas das questões-problemas que, a nosso ver, constituem os desafios da formação e do trabalho docente. É aí, sobretudo, que temos percebido o abismo entre os conteúdos curriculares oficiais propostos aos professores e a vida dos sujeitos do ensino e da aprendizagem. Em maio de 2018, por ocasião da Chacina de Pau D’Arco, ${ }^{1}$ como introdução à discussão sobre conflitos agrários, realizou-se uma pesquisa com os alunos do Assentamento Oziel Pereira, onde um dos autores do texto atua como professor das disciplinas de História e Aspectos da Vida Cidadã. A primeira parte do formulário era um levantamento do perfil dos alunos: $84 \%$ eram assentados, $69 \%$ dos lotes eram de 5 alqueires. ${ }^{2}$ Apenas a família de três alunos tinha terra com medida superior a 7 alqueires, uma família somando 54 alqueires. No entanto, à pergunta sobre a profissão dos pais, $45 \%$ responderam serem filhos de fazendeiros, e à pergunta sobre o que pensavam de ocupação de terras, $62 \%$ disseram achar errado, e entre estes, alguns avaliaram, na fase de discussão, que invasor de terra tinha de morrer.

Considerando que Oziel Pereira, que deu nome à Vila, foi uma liderança do Movimento Sem Terra assassinada na Chacina de Eldorado dos Carajás em 1996, na mesma luta que resultou no assentamento onde vivem os alunos que responderam ao questionário, os dados revelam um problema que não pode ser ignorado pelo professor que atua na perspectiva da educação histórica como processo de ampliação da consciência do e sobre o mundo. Nessa acepção, a questão é sobre "qual o sentido histórico da formação que esses alunos têm" e "que consciência desenvolvem". 
Gráfico 1 - Perfil discente

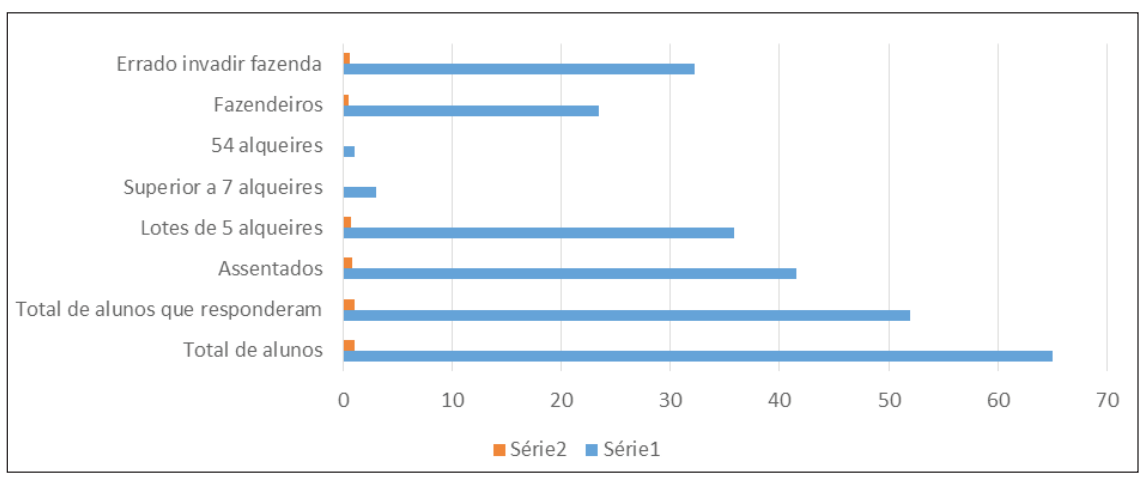

Fonte: elaborado pelos autores com base no questionário aplicado em sala.

Há espaço para a vida no ensino de história? Num momento em que os discursos oscilam entre a homogeneização dos sujeitos por meio do currículo comum e da guerra contra a escola enquanto lugar de plenitude humana sob o argumento da escola com/sem partido, a impressão é que há pouco espaço para a arte, a beleza, a alegria, a luta e o sofrimento aos que vivendo nesse mundo, sobretudo no mundo rural, vão à escola. Os fins impostos à educação, substanciados em um material didático, em métodos de ensino e formas de avaliação massivos, não deixam dúvidas de que a história que se pensa na escola, salvo poucas exceções, é uma ficção com pouca margem para que se possam vislumbrar pessoas e suas realidades concretas. Nesse sentido, é razoável problematizar o lugar do ensino de história com base em temas, sujeitos e contexto específico. É notável, particularmente depois da implantação do Exame Nacional do Ensino Médio (Enem), a força que o discurso do currículo comum ganhou. Do material - especialmente o Livro Didático - às propostas metodológicas, supõe-se uma homogeneidade do processo de ensino, no que diz respeito tanto aos conteúdos quanto à suposta aprendizagem, tão na mesma medida que pode ser metrificada, pesada e numerada pelos critérios do Instituto Nacional de Estudos e Pesquisas Educacionais Anísio Teixeira (Inep), autarquia ligada ao Ministério da Educação. Isso se faz sob a forma de uma avaliação massiva, com provas elaboradas por "alienígenas" e questões decididas, depois, mediante sorteio. Não há, nesse contexto, espaço para as singularidades, muito embora o discurso, nos parâmetros curriculares nacionais, seja 
do respeito à diversidade, inclusive às diversidades regionais. Não há espaço para a existência dos sujeitos, mesmo quando todo o discurso seja o da cidadania, sob a forma de formação para a autonomia. Obviamente, essa estrutura precisa ser mudada, e avanços são possíveis mesmo com essa estrutura - e apesar dela. A viabilidade da mudança, no campo da ciência História, e por consequência do seu ensino, tem sido indicada por muitos, em tempos diferentes. É nesse sentido que essa reflexão constitui proposta de que, no contexto do Araguaia-Tocantins, o ensino massivo e amorfo de uma história eurocêntrica e desnuda seja substituído pela educação histórica, cujo processo de ensino se funda na formação da consciência histórica, e não no ensino de fatos históricos isolados e descontextualizados.

Jörn Rüsen, teórico alemão que, como bem o demonstra Barom (2015), passou a ser conhecido no Brasil a partir dos trabalhos de professores vinculados a algumas universidades brasileiras, entre elas a Universidade de Brasília (UnB), a Universidade de São Paulo (USP), a Universidade Federal da Paraíba (UFPB), a Universidade Federal do Paraná (UFPR) e a Universidade Federal de Goiás (UFG), é uma referência para o entendimento do conceito de educação histórica. Para Rüsen (2015), a educação histórica é um processo de atribuição de sentido à temporalidade. A temporalidade, ou, para ser mais específico, os seus sentidos para os sujeitos que a vivem, é chave para o entendimento da consciência histórica. O passado é o tempo da experiência, demandada enquanto tal pelos dissabores do presente, que se orienta não apenas a partir dessas experiências do passado, mas a partir das projeções sobre o futuro. Pode-se dizer que o presente demanda o passado. Esse saber do passado na sua relação com o presente é condição para as projeções de futuro, para o reconhecimento, pelo sujeito, das estruturas que o cercam e das possibilidades de mudança. Consciência de si e do chão concreto do mundo vivido é o que aproxima a teoria rüseniana do pensamento e da prática pastoral de Josimo, o padre que se engajou às últimas consequências na luta que sendo pastoral, era também formação de consciência histórica, fundamento da discussão proposta neste texto.

A consciência histórica não é, portanto, apenas um saber sobre o passado, e sim sobre os sentidos do passado no presente e sobre as possibilidades de ação a partir desse saber. Maria Auxiliadora Schmidt e Tânia Braga Garcia (2005), professoras ligadas à Universidade Federal do Paraná (UFPR) que têm incentivado pesquisas em educação histórica a partir do contexto ao qual estão 
vinculadas, definem a consciência histórica, com base no pensamento rüseniano, como o movimento que dá à vida uma concepção do curso do tempo. Para elas, o passado se apresenta como experiência ao mesmo tempo que também é orientação para o presente. Nas palavras do próprio Rüsen (apud Martins; Schmidt, 2011, p. 57), "a consciência histórica trata do passado como experiência, nos revela o tecido da mudança temporal dentro do qual estão presas as nossas vidas, e as perspectivas futuras para as quais se dirige a mudança”.

A filósofa de origem húngara Agnes Heller (1993) avalia que a consciência histórica é a percepção que os indivíduos têm de "estar no mundo", o que, na sua análise, independe de educação formal. Vale lembrar que a autora contribuiu significativamente com os estudos históricos a partir de suas reflexões sobre a historicidade do cotidiano. Rüsen e Agnes Heller se aproximam na definição de consciência histórica, mas, afastados no tempo e no espaço, também se distanciam em alguns aspectos de suas respectivas formulações teóricas. Há, portanto, uma instrumentalidade positiva da história enquanto saber. É verdade que a intelectualidade busca, a todo custo, expurgar termos como instrumentalidade, utilidade ou serventia, porém, a educação histórica, tal como a propõe Rüsen, é a possibilidade de que a história seja alguma coisa além da mera ilustração. Esse sentido de instrumento de feitura da autonomia de sujeitos conscientes da sua história e da sua historicidade aproxima o pensamento rüseniano do de Paulo Freire. A educação em Paulo Freire é, antes de tudo, um processo de formação de autonomia. Essa autonomia, no entanto, decorre de uma tomada de consciência. Esta, em Freire, não se confunde com um conjunto de saberes abstratos sobre um mundo alheio ao sujeito do conhecimento, pelo contrário, como ele diz, a leitura do mundo precede a leitura da palavra, ou seja, antes da educação formal, e concomitante a ela, há um mundo de saberes sobre o mundo de quem aprende. A leitura é importante, então, porque possibilita uma releitura do mundo vivido ao mesmo tempo que esse mundo é a base sobre a qual se processa a crítica formal, viabilizada pelo processo de ensino.

É importante, todavia, esclarecer que Jörn Rüsen parte da crítica ao ensino de História na Alemanha que, até a década de 1970, confundia a didática da história com metodologias de instrução e psicologia da educação para, aproximando-se da teoria da história, propor a discussão da didática da história à luz da produção historiográfica, ou seja, do seu próprio campo. Nesse cenário, 
pode parecer contraditório aproximar Paulo Freire - pedagogo e, por consequência, também pensador das "metodologias de instrução" - de outro intelectual que parte da crítica a essas "metodologias de instrução" (Rüsen, 2006, p. 9; Rüsen apud Martins; Schmidt, 2011, p. 28), identificadas como tendência de pedagogização do ensino de história. Entretanto, a questão fundamental é que Jörn Rüsen não conheceu Paulo Freire, do contrário teria descoberto que existe, em outra área do conhecimento, algo mais próximo da sua discussão - isto é, aquilo que Freire fez, escreveu e disse sobre a educação. Esses dois teóricos, Freire e Rüsen, que pensaram a educação a partir de lugares tão diferentes, constituem, neste artigo, chave de leitura para a proposta de uma educação que possa ter na luta dos sujeitos do campo, matéria de estudo, e no exemplo do engajamento daqueles que se comprometeram com a causa, exemplo histórico, como é o caso do padre Josimo Moraes Tavares. Não se trata de exclusão da proposta curricular oficial, mas composição desta com a história dos sujeitos que sofrem, lutam e morrem no campo.

Josimo nasceu em Marabá, no Pará, no ano de 1953. É filho de nordestinos migrantes, movimento que, à época, embora não fosse forte, ${ }^{3}$ era contínuo. Havia os migrantes que buscavam terras livres para cultivar; aqueles que procuravam algum garimpo da região na esperança de fazer a sorte; e o grupo que migrava apenas para, na condição de empregado, garantir algum sustento à família. Não se pode dizer, no entanto, que homens e mulheres estavam presos às suas expectativas; muitos queriam terras, mas mudavam o destino da caminhada na extração de castanha a serviço de grandes grileiros, como a família Mutran. Ademais, havia garimpeiros que, desiludidos, partiam para o cultivo de alguma posse, reproduzindo a vida na calmaria do trabalho na terra. Certo é dizer, desse movimento migratório, que ele foi sempre incerto. Além disso, pelo infortúnio que muitos encontraram, famílias se perderam, filhos foram mortos, mães ficaram viúvas - algumas de esposos vivos - e filhos ficaram órfãos.

Pouco se sabe sobre o pai de Josimo. Depreende-se de alguns estudos (Aldighieri, 1993; Le Breton, 2000; Silva, A., 2011) que se perdeu entre atividades de garimpo e trabalhos nas fazendas de gado e de extração de castanha da região. Os homens se perdiam com muita frequência nas fazendas e nos garimpos do Pará não só naqueles anos de início da década de 1950, mas, com muito mais frequência, entre as décadas de 1970 e 1980. A perdição era tão 
variável na sua forma quanto na frequência. Havia os que, depois de explorada sua mão de obra, eram assassinados e por isso não retornavam; os que não voltavam à família porque não admitiam o fracasso dos seus projetos - a ideia era bamburrar ${ }^{4}$ e retornar rico - e, por fim, os que se distanciavam tanto da família, no tempo e no espaço, que acabavam perdendo o vínculo e, posteriormente, formando outra família. Qualquer um desses casos pode ter sido o destino do pai de Josimo, uma vez que todos eles eram comuns aos muitos homens que se perderam, e ainda se perdem, na Amazônia.

Com 11 anos, em 1964, ano do golpe civil-militar que pôs fim ao governo democrático, Josimo entrou no Seminário Menor Leão XIII. Sua formação foi marcada pela convivência com religiosos Orionitas e Lazaristas. Assim, desde os seus primeiros anos de seminário, Josimo conviveu com o que havia de melhor no sentido de conservadorismo dentro da Igreja Católica, vez que tanto Lazaristas quanto Orionitas enquadravam-se naquilo que, seguindo a classificação proposta por Godofredo Deelen (apud Alves, 1979), pode denominar-se de Igreja Papista - aquela cujo clero, especialmente na pessoa do seu líder, um bispo ou provincial, "é um moderado que se deixa impressionar terrivelmente pelo perigo comunista, o que lhe provoca o medo ao comprometimento social, tal como o medo a palavras como revolução e reformas" (Alves, 1979, p. 87, grifos no original). Mas o jovem seminarista também conheceu, sobretudo no curso de Filosofia em Petrópolis, o que havia de mais progressista na Igreja Católica no Brasil, tendo sido aluno de Leonardo Boff e de outros teólogos da Libertação.

Não há dúvida, considerando não só a produção intelectual de Josimo, mas toda a sua vida e o sacrifício final, a sua morte, que a Teologia da Libertação e sua própria origem, enquanto pessoa, o influenciaram muito mais que a formação lazarista e orionita no seminário. A primeira característica da sua escrita é a marca da sua origem e o sentimento comum em relação à luta do povo. Mesmo no seminário, essa é a matéria da sua poesia, como foi, depois de ordenado, tema de suas peças de teatro e de suas homilias. A produção teórica de Josimo, como a conjuntura que o assassinou, expressam o paradoxo de um país dividido entre a euforia da abertura política e a dureza da repressão militar no campo. ${ }^{5}$ Josimo foi ordenado padre em 1979, num ambiente politicamente promissor, a abertura. Naquele ano o presidente Ernesto Geisel sancionou a Lei da Anistia. Em dezembro de 1978 já tivera fim o Ato Institucional 
$\mathrm{n}^{\circ}$ 5. Parecia ser um tempo tão promissor que foi extinto o bipartidarismo e, 3 anos depois, em 1982, foram realizadas eleições diretas para governador. No campo, contudo, havia uma guerra em curso.

No bojo do processo de mudança, os camponeses empreenderam grandes mobilizações no sentido de garantir a realização da reforma agrária, de assegurar a permanência em suas terras, adquiridas não pela formalidade do título, mas pelo tempo de moradia e trabalho. Essa mobilização resultou, especialmente nos anos subsequentes à abertura e, portanto, na redemocratização, uma tomada de posição decisiva do governo em favor dos latifundiários e contra o camponês. Em consequência dessa opção preferencial pelos ricos, no campo a ditadura apenas recrudesceu.

O Decreto-Lei ${ }^{\circ} 1.767$, de $1^{\circ}$ de fevereiro de 1980, criou o Grupo Executivo de Terras do Araguaia-Tocantins (Getat), que depois, no mesmo ano, foi subordinado à Secretaria Geral do Conselho de Segurança Nacional, o que significava, como bem discute José de Souza Martins (1984), a militarização da questão agrária na Amazônia. Não se tratou, no entanto, da intervenção do Estado para garantir direitos, e sim da intervenção do Estado para manter a ordem, fundada como estava essa ordem na força do mais forte e na violência contra o mais fraco. Ordem imoral e injusta. E é nesse sentido que se deve entender a intervenção do Estado, na forma da repressão que se abateu sobre os camponeses da região do Bico do Papagaio, como opção preferencial pelo latifúndio e por toda violência que esse projeto representa. O golpe civil-militar, como bem o demonstra Martins (1983; 1991), foi um golpe contra a luta camponesa que, antes de qualquer coisa, era uma luta pela efetiva função social da terra, prescrita no texto da Constituição brasileira.

De acordo com os dados levantados por Pereira (1990) entre 1967 e 1986, a Central Única dos Trabalhadores (CUT) identificou 24 enfrentamentos entre grileiros e posseiros, envolvendo aproximadamente 1.500 famílias e cerca de 7 mil pessoas. Considerando que o meio rural não é o lócus específico de atuação da CUT, é razoável supor que os dados são incompletos. Para se ter uma ideia, um relatório da Comissão Pastoral da Terra (CPT) de 21 de novembro de 1984 (Silva, A., 2011) informa que entre agosto e novembro daquele ano ocorreram, no Bico do Papagaio, 600 despejos, 108 casas queimadas, 2 fazendeiros mortos, 7 assassinatos entre lavradores e lideranças sindicais e 27 trabalhadores presos, além de dezenas de espancamentos realizados pelo 
consórcio entre Polícia Militar e pistoleiros a serviço dos fazendeiros locais. Longe de se diluírem, os conflitos seguiram nos anos seguintes. Chaves (2015) informa que, tendo ocorrido 712 conflitos agrários no Brasil no ano de 1985, 73 deles foram no Bico do Papagaio, ou seja, 10,6\% dos conflitos agrários de todo o país ocorreram nessa região. A pesquisadora (Chaves, 2015, p. 94) conclui que "estamos diante da maior região de concentração dos conflitos no Brasil. São, portanto, os conflitos no campo e a violência a marca dos processos que a constituíram". Sim, o Bico do Papagaio constitui-se por uma ocupação que, quando não marcada por conflitos entre camponeses e indígenas, o foi por camponeses e fazendeiros.

A obra intelectual do padre Josimo, salvo alguns poucos textos, tem como público-alvo os camponeses. Ele elabora uma literatura da urgência da justiça, que precisa ser feita no mundo dos viventes e não depois dele. Em correspondência à mãe, dona Olinda, de 23 de maio de 1978, Josimo, depois de demonstrar preocupação com a situação financeira dela e dos conhecidos, escreve: "há muitas pessoas sendo injustiçadas porque os patrões pagam mal. Outra injustiça que nasce da falta de uma política que pense mais no povo é a ausência de emprego" (Tavares, 1999, p. 100). ${ }^{6}$ Em seus textos particulares a injustiça, tema recorrente, é identificada como a falta de saúde, de emprego, de moradia, de educação e, especialmente, como a falta de terra para trabalhar. A "libertação", expressão quase tão recorrente quanto "justiça”, é fim para o qual se dirige a luta, à qual devem se comprometer o padre e o povo. Essa não é uma perspectiva circunstancial, é a forma como Josimo compreende o sentido do seu "estar no mundo" e "ser no mundo". Ao bispo, Dom Cornélio, em correspondência de 30 de abril de 1974, depois de dizer que Deus é a realidade, escreve que “oração não é uma fórmula. É mais uma atitude" (Tavares, 1999, p. 56). Sua correspondência é reveladora do drama de se viver no extremo norte de Goiás, na região do Araguaia-Tocantins, e, dentro dessa região, na microrregião do Bico do Papagaio entre 1970 e 1980. No conjunto da sua obra, Natal: a solidariedade dos pobres na luta por mais liberdade e justiça é, entre os textos públi$\cos ,{ }^{7}$ o mais eloquente.

Nesse texto se reproduzem as condições de vida a partir do que dizem os diversos personagens. Joana, a mulher sofrida, clama por justiça contra o sofrimento e a humilhação, mas nega, quando lhe é oferecida, a ajuda do comerciante, que estende o braço como oferta de esmola; quando a disposição em 
ajudar parte de um grupo maior, a resposta é "não há consolo na lágrima, nem amparo na esmola!” (Tavares, 1999, p. 87). Somente a Miguel, o igual, aquele que divide a sorte da classe social, é apresentado o rosário de sofrimentos que a aflige. Ela conclama o companheiro à luta, ação que aparece no discurso dos trabalhadores como o único caminho para a libertação. Assim, a exortação não é só para a conversão dos que praticam a injustiça, os ricos, mas também aos que não se unem na luta, os pobres. O empoderamento, como consequência da luta, implica, na trama textual, não só a conquista da terra, mas de toda a dignidade a que se tem direito, o que o texto antevê depender também do engajamento e da ascensão política dos trabalhadores.

Josimo não era só discurso. A igreja da Libertação, como esclareceu frei Henri Burin des Roziers (entrevista de 13 fev. 2010), foi aquela que compreendia a práxis teológica como a reflexão suscitada pelo chão da vida. Como atestaram seus paroquianos, Josimo levava isso às últimas consequências. Nos despejos fazia-se presença junto aos trabalhadores, inclusive dormindo como se podia dormir e comendo do que podiam comer, para depois denunciar a violência às autoridades. ${ }^{8}$ Foi por essa presença solidária e, ao mesmo tempo, por suas práticas de denúncia, que padre Josimo sofreu processo difamatório, posteriormente foi preso, sofreu uma tentativa de assassinato e, por fim, aos 33 anos de idade, foi assassinado com dois tiros nas costas, em 10 de maio de 1986. No dia 27 de abril de 1986, o carro que Josimo dirigia foi alvo de vários disparos, circunstância da qual saiu ileso. Lúcido do ambiente que o cercava, declarou à assembleia dos padres da Diocese de Tocantinópolis, que o pressionavam a deixar a região para evitar o pior: "tenho que assumir. Agora estou empenhado na luta pela causa dos pobres lavradores [...] Morro por uma causa justa” (CPT, 1996, p. 17-18). Terminou assassinado 13 dias depois dessa declaração.

A primeira questão fundamental a se pensar, no campo do ensino de história, da trajetória do padre Josimo, é se essa temática é importante enquanto conteúdo de ensino. Quando se considera o ensino dentro das propostas majoritárias, inclusive do engodo que é o currículo, esse seria um tema completamente descabido, mesmo porque sofreria pressão daqueles que levantam verdadeiras querelas em torno de todo conteúdo crítico, sob a acusação que se convencionou chamar escola com partido, que demandaria a luta por uma escola sem partido. ${ }^{9}$ É preciso, todavia, pensar no perfil da comunidade escolar 
do Araguaia-Tocantins, até mesmo daqueles estudantes do acampamento Padre Josimo, em Carrasco Bonito, Tocantins, ou do Assentamento $1^{\circ}$ de Março, em São João do Araguaia, Pará, ou, ainda, da comunidade escolar da Vila Oziel Pereira, em Piçarra, Pará. Todas essas comunidades se formaram da luta pela terra, todas, matéria do sonho do povo, com quem também sonhou o padre Josimo. Mas o currículo, especialmente o quase exclusivo material a que o professor tem acesso, o Livro Didático - e não são poucos os professores que, de fato, quando muito têm apenas o Livro Didático -, silencia não apenas sobre os sujeitos que se engajaram na luta do povo, mas também sobre o povo e sua luta.

A considerar, por exemplo, a coleção de História adotada na Escola Estadual Alice Silveira Lima, do município de Piçarra, responsável pelo Sistema Modular de Ensino que funciona na Vila Oziel Pereira, um dos maiores assentamentos do Sul do Pará, além de não haver espaço para as lutas do povo, temas como ditadura e autoritarismo são secundários. Para se ter uma ideia, a coleção \#contato história adotada na escola em 2018 trata o nazismo e o fascismo em cinco parágrafos de texto. A ditadura militar é informada com poucas possibilidades reflexivas. O livro foi adotado na escola - não se sabe bem quem o escolheu - e se dirige ao povo que vive no palco da Guerrilha do Araguaia, mas não diz uma linha sobre esse fato. O povo, nem quando o fato é de grande repercussão, se vê reconhecido no livro. Os quatro assentamentos - Oziel Pereira, Anajás, $1^{\circ}$ de Março e Ponta de Pedras, no qual um dos autores deste artigo trabalha - são marcados pela história do trabalho escravo, com casos de grande repercussão, como da Fazenda Bamerindus nos assentamentos Oziel Pereira e Anajás, mas o que o livro diz sobre o trabalho escravo contemporâneo? O Livro Didático, que é quase a exclusiva forma do currículo em sala de aula - só não é exclusivo porque o currículo em si é diverso e, nesse caso, além de considerar o mundo e o protagonismo dos estudantes, é preciso levar em conta a subversão do professor -, é produzido para os alunos dos grandes centros. Esse é o mundo do currículo, e é preciso dizer mais: o Livro Didático não é o livro da periferia. O Livro Didático não é o livro da roça nem o dos ribeirinhos, tampouco é o livro do povo. O Livro Didático é o livro do Exame Nacional do Ensino Médio (ENEM). E não há um meio mais injusto, autoritário e pretensioso que esse sistema que avalia alunos diferentes, de condições históricas, econômicas e sociais diferentes, de contextos e de escolas diferentes, 
como se fossem iguais. O Enem, ao que parece, pretende que os estudantes ribeirinhos, ou os alunos da Vila Oziel, que estudam numa escola sem ventilação, sem lanche e sem qualquer material didático, exceto o livro, até ele em quantidade insuficiente, e que têm professores que vão à escola quando podem, e em muitos casos, apenas quando querem, estejam ao final do Ensino Médio no mesmo nível do Liceu de Goiânia, das boas escolas baianas ou das melhores escolas de Curitiba. Esse contexto tem resultado em evidentes processos que corroboram a manutenção da desigualdade, sobretudo pela equiparação educacional de realidades diferentes, o que aponta para a superficialidade no trato com os direitos sociais básicos, reconhecidos constitucionalmente, e evidencia a crueldade com que o Estado tem tratado os grupos sociais considerados subalternos.

Reconhecemos o discurso quase unânime em favor do Livro Didático. Dos primeiros estudos aos mais recentes diz-se que se trata do quase exclusivo contato que muitos alunos têm com a leitura. Sabemos que muitos estudantes têm o livro, mas não há como saber se, efetivamente, o leem. Reconhecemos a validade do argumento culturalista, especialmente daquele inspirado nos estudos de Chartier (1990), para quem a leitura é um processo dinâmico e criativo, o que significaria que a utilidade do livro não está em si, mas nos seus usos. É verdade, a validade do livro está no uso - e, como professores, o utilizamos. Mas o uso é também a grande desgraça do Livro Didático. O que se pode depreender de estudos como de Ana Célia Silva (2011) Miranda e Luca (2004) é que, além dos silêncios, a persistência do caráter de manual do Livro Didático sustenta o comodismo parasitário de alguns professores que, além de não terem tido boa formação inicial, ou simplesmente terem sido relapsos na universidade, comodamente apoiam-se no livro e continuam com suas deficiências intelectuais e políticas. E os alunos? Nas circunstâncias a que estou me referindo, também se apoiam no livro para devolver aos professores recortes dos livros como se fossem respostas suas às perguntas, que também não são dos professores.

Pesquisa do início da década de 1980 (Franco, 1982), quando o Livro Didático ainda não era tão disseminado, já indicava que nas 347 escolas pesquisadas, em São Paulo, 80\% dos professores utilizavam o Livro Didático como principal material e, desses professores, a maioria declarava utilizar o livro porque faltava tempo para preparar as aulas. Em outras palavras, para esses 
professores, o Livro não era utilizado por ser bom em si, mas porque, para alguns deles, não havia outra opção, e para outros faltava tempo para preparar as aulas. Também no nosso campo de atuação a utilização do Livro Didático, em si, é um desafio. Nos 3 anos de atuação na Escola Oziel Pereira, mesmo com poucos alunos - média de 60 alunos por módulo divididos nas três séries do Ensino Médio -, nunca foi possível ter Livro Didático em quantidade suficiente para todos. Em nossa perspectiva teórico-prática esse livro, não disponível em quantidade suficiente, é, antes, insuficiente em qualidade. O Livro Didático, entendido como material de apoio, não raro foi utilizado mais para discutir o seu silêncio que para reproduzir seu conteúdo - conteúdo, no entanto, sempre discutido. Reconhecemos, todavia, que nesse contexto de trabalho, especialmente para uma série de professores em atividade sob contrato precário, alguns com formação inicial também precária e atuação em área diversa da sua formação, o Livro Didático é uma tábua de salvação. E isso é tão sério que a ausência do Livro é remediada, em muitos casos, com a reprodução de suas páginas, as famosas "xerox" vendidas aos alunos a preços majorados, o que em si, também é um problema ético. Cremos, ante esse quadro, não ser exagero dizer que a existência, e permanência, do Livro Didático, tal como é, tem se justificado não pelo seu valor intrínseco, mas pela miséria da Educação brasileira. É importante pontuar isso porque falar do ensino de história requer discussão sobre a forma como os conteúdos dessa disciplina chegam ao espaço da sala de aula e sobre os conteúdos que não chegam à sala de aula. É preciso problematizar a forma como a Amazônia, o Araguaia-Tocantins e particularmente o Bico do Papagaio são representados/invisibilizados nesses livros.

Na perspectiva da educação histórica, a preocupação central do processo de formação é a consciência histórica que, sendo a capacidade humana de situar-se no tempo, tem como referência a experiência do tempo, que não pode ser outra senão aquela que lhe faz sentido. Essa não é uma ideia apenas rüseniana. De certo modo, quando Marc Bloch (2001, p.55) se referiu à história como a ciência dos homens no tempo, quis fixar a experiência humana como elemento central da pesquisa histórica. Ademais, o movimento historiográfico de que participou e que ficou conhecido como Annales avançou nessa compreensão não só quando ampliou o sentido das experiências humanas pelo reconhecimento da diversidade das fontes, mas também quando, em consequência, ampliou a temática dos estudos históricos. 
A didática da história é o espaço ideal, na análise de Rüsen, para que se pensem as formas do desenvolvimento da consciência histórica. A questão, nessa acepção, não é tanto sobre as metodologias, mas sobre o sentido da aprendizagem em relação ao sujeito do conhecimento. Nesse caso, o conhecimento histórico e os sentidos da sua apreensão não constituem um bloco de informações, tampouco se pode restringir a questão à cognição, uma vez que "o estímulo e a força pulsional do aprendizado histórico encontram-se nas necessidades de orientação de indivíduos agentes e pacientes" (Rüsen apud Martins; Schmidt, 2011, p. 44) e tais necessidades decorrem das contingências das experiências temporais. A motivação é, assim, fator de mobilização do passado. A motivação não está explicitada apenas nas agruras do tempo em que se vive. Rüsen (2015) considera que o próprio agir humano é motivado pelo que chama de impulsos da vontade, ou "impulsos para o agir", em referência a Max Weber, e "vontade de poder", conforme Nietzsche. Nesse impulso para o agir as emoções constituem elemento fundamental. Isso posto, conclui Rüsen que a percepção das experiências e a própria narrativa histórica não estão livres da subjetividade característica da condição humana.

Neste ponto retoma-se o tema do ensino de história no Araguaia-Tocantins e a trajetória do padre Josimo para conjecturar sua relação com a proposta rüseniana de educação histórica. A primeira tipologia da consciência histórica na classificação de Rüsen se refere ao lugar das tradições na formação do pensamento histórico. Nesse caso, "as tradições são elementos indispensáveis de orientação dentro da vida prática, e sua negação total conduz a um sentimento de desorientação massiva" (apud Martins; Schmidt, 2011, p. 62). No contexto do Araguaia-Tocantins as possibilidades de leitura do tipo tradicional são amplas. Primeiro, a negação dos conflitos repousa na cristalização de um sentimento de que os camponeses, e os pobres em geral, não têm história. E pior, a história que têm é a história da criminalização de suas práticas de resistência. No caso de Josimo, embora padre, era preto e não estava sentado à mesa dos ricos. Entretanto, o tipo tradicional também pode ser lido, de forma mais positiva, a partir da centralidade do tipo de Igreja que Josimo representava e da defesa da terra como tradição de um povo, povo muito mais decidido à luta que conformado à violência que recaía sobre os que lutavam. Há uma ritualística e um discurso simbólico da Igreja progressista. O martírio de Josimo se confunde com essa tradição. As inúmeras mortes constituem toda uma simbologia que configura uma primeira 
forma de pensamento histórico sobre a luta camponesa no Araguaia-Tocantins. Outro exemplo é a toponímia, Oziel Pereira, que indica um esforço de memória da luta que se contrapõe ao esforço oficioso, expresso nas propostas curriculares, de marginalizar a luta e a memória do povo.

O segundo tipo rüseniano de formação da consciência histórica é o exemplar. Essa é a matéria da nossa história desde o século XIX, quando ela se estruturou enquanto disciplina. A história de modelos a serem seguidos, ou a historiae vitae maestrae, admitida pelo próprio Rüsen (apud Martins; Schmidt, 2011, p. 65) como "uma máxima tradicional na tradição historiográfica ocidental”. O passado ensina o que fazer e o que não fazer. Nas palavras de Rüsen ( apud Martins; Schmidt, 2011, p. 65), "a consciência histórica se refere à experiência do passado na forma de casos que representam e personificam regras gerais de mudança temporal e a conduta humana". Essa conduta, no presente, pode-se dizer, é definida pelas regras gerais dadas a conhecer pela experiência. Os tipos são complementares e, assim, a luta pela terra, o trabalho de Josimo e a luta dos camponeses podem constituir o quadro de orientação, considerando o tipo exemplar de consciência histórica. É possível, como os alunos demonstraram na atividade mencionada no início deste artigo, que a tradição de exclusão e os exemplos de repressão se imponham. Mas também é possível que a resistência daqueles que foram à luta, como Oziel Pereira e o próprio Josimo, constitua exemplo na luta contra a opressão. As pessoas podem decidir-se sobre a questão agrária na Amazônia tendo como referência o legado daqueles que, anteriormente, se comprometeram com a luta pela terra. No caso aqui proposto, as possibilidades, ainda tendo como referência o tipo exemplar, são bem mais amplas que o exemplo sugerido por Rüsen. Aqui, não se trata apenas da questão agrária, mas do posicionamento em relação a questões caras ao povo brasileiro no momento.

O terceiro tipo é o crítico. Nesse caso, pode-se supor que a morte de Josimo não foi necessária. Muitos trabalhadores morreram porque, descrentes da justiça, partiram para a violência. A própria Igreja em Tocantinópolis, à época, queria mandar Josimo a Paris, de modo a evitar - o que hoje cai bem a essa Igreja - o seu martírio. A própria Reforma Agrária, enquanto projeto, pode ser refutada. De fato, tal como é conduzida no Brasil, a Reforma Agrária é um grande engodo. Contranarração e mudança são os termos-chave da tipologia crítica. Para Rüsen (apud Martins; Schmidt, 2011, p. 67), "por meio dessa contranarração podemos desmascarar uma história determinada como 
um engano, desprestigiá-la como uma informação falsa". E acrescenta: "podemos narrar uma contra-história breve, por exemplo, a história de como as leis mudaram com o passar do tempo" (apud Martins; Schmidt, 2011).

O tipo genético, ao mesmo tempo que admite a releitura dos modelos anteriores, enfatiza a mudança temporal, não as tradições, os exemplos ou a negação em si. Nas palavras de Rüsen, "a mudança temporal se despojou de seu aspecto ameaçador e se transformou no caminho no qual estão abertas as opções para que a atividade humana crie um novo mundo" (apud Martins; Schmidt, 2011, p. 69). O tipo genético é a síntese de possibilidades extraordinárias para o ensino de história. É uma expressão extraordinária da riqueza da proposta educacional mediada por conteúdos da experiência histórica do povo para a formação do povo. É, enfim, um meio de efetividade daquilo que Paulo Freire chama de educação para a autonomia (1996), ou educação como prática da liberdade (1983). É nesse contexto que se deve retomar a questão da razoabilidade da discussão sobre a disciplina de história a partir de temas, de sujeitos e de contexto específico. A resposta agora é simples, mas na forma de outra questão: há margem para a perspectiva de futuro aos indivíduos privados da sua própria experiência histórica? Ou ainda, são possíveis respostas adequadas às crises do presente sem a reconstituição da temporalidade?

Em Rüsen, os homens são sujeitos da história, mas são sujeitos da sua história, e não da história que lhes é alheia. É intrínseca à constituição dessa história a orientação temporal que atribui sentido ao presente, e o presente é o campo de ação dos sujeitos. O ensino de história, nessa perspectiva da educação histórica, precisa entender a sala de aula como espaço de produção de saber. Necessita, como defendem Schmidt e Garcia (1999), aproximar metodologia de produção do saber histórico com metodologia do ensino de história. Essa é a conclusão para a qual converge toda essa discussão: pensar a escola como espaço de produção de saber para, a partir dessa nova visão de escola e de aula propor, com a adequada orientação do professor, o presente como problema e a pesquisa histórica, a partir da história local, como resposta.

Tratando adequadamente a temporalidade, inclusive cuidando para não incorrer em anacronismos, é possível discutir os conteúdos de história propostos para o Ensino Médio partindo dos problemas do Araguaia-Tocantins. No entanto, o que se propõe aqui não é apenas ter o Araguaia-Tocantins como dinâmica problematizadora das aulas de história, embora isso também deva 
acontecer; a defesa é de que os conflitos agrários se tornem objeto de estudo nas salas de aulas das escolas amazônicas, especialmente no Araguaia-Tocantins, no Bico do Papagaio, nas escolas de assentamentos, enfim, no mundo rural brasileiro. Torná-los conteúdos de estudo não é ignorar os problemas intrínsecos às formas de luta, mas, pensando no tipo crítico proposto por Rüsen, submeter à crítica as estratégias de luta dos povos do campo, conjecturar outras possibilidades. A questão, enfim, não é de uma opção discursiva, mas de tornar esse tema objeto de estudo.

Levando em conta os retrocessos políticos das decisões tomadas especialmente nos governos Temer e Bolsonaro, é razoável dizer que o Brasil retoma a lógica denunciada, entre outros, por intelectuais como José de Souza Martins (1984), René Armand Dreifuss (1981), Ricardo Rezende Figueira (1986) e o próprio Josimo Moraes Tavares (1999), de governo para os latifundiários. A Comissão Pastoral da Terra (1986) esforçou-se por demonstrar que a chamada Nova República, aquela governada pelo chefe da principal oligarquia do Maranhão, José Sarney, representou o mais cruel engodo para os movimentos sociais do campo, pois o pequeno aceno em direção à Reforma Agrária recrudesceu a violência do latifúndio, resultando na criação da União Democrática Ruralista (UDR). Cruel porque, como o demonstra Ana Célia Silva (2011), diante da pressão, comum a todos os conflitos sociais, o governo tomou o partido do latifúndio. Finalmente, cruel porque a militarização da questão agrária consolidou o processo de redemocratização, ou seja, pacificou as elites econômicas a partir de um acordo que feria de morte o sonho de permanecer na terra, projeto dos camponeses do Araguaia-Tocantins e, especialmente, daqueles que lutavam no Bico do Papagaio. Essa dinâmica de governabilidade, fundada no acordo político-econômico das elites políticas com as elites latifundiárias - que em muitos casos se confundem -, é ainda a dinâmica da política no Brasil. Não fosse esse o caso, o discurso em prol da reforma trabalhista e sua aprovação no Congresso seriam incompreensíveis. Não fosse esse o caso, a luta política em torno da legislação da criminalização do trabalho escravo seria absurda e serôdia, obsoleta. Não fosse esse o caso, não estaria em curso o maior projeto de subtração de direitos aos pobres em favor dos mais ricos.

O Massacre de Eldorado dos Carajás, o Massacre de Pau D’arco, a violência no Bico do Papagaio e a Guerrilha do Araguaia ${ }^{10}$ são todos temas históricos que precisam entrar na sala de aula como objeto de estudo. A metodologia 
adequada a essa proposição é matéria para outra discussão, e propomos a experiência das professoras Maria Auxiliadora Schmidt e Tânia Braga Garcia (2005) como ponto de partida. De testemunho podemos dizer que o nosso esforço é de contextualização. É preciso discutir os problemas locais nos seus entrelaçamentos com fatos mais gerais. O pobre precisa saber não apenas por que é pobre, mas das estruturas que são elaboradas para que assim permaneça. A violência contra o negro, especialmente o racismo; a violência contra a mulher, e os mandonismos que tornam privado o que deveria ser público não podem estar ausentes das discussões, dos debates sobre história do Brasil numa perspectiva de educação histórica. Mas o que dizer das revoluções europeias? O que dizer das grandes civilizações ocidentais e orientais? Tudo que se possa dizer desse conteúdo, de sua temporalidade e dos fatos que constituem o saber sobre eles. Mas, ao mesmo tempo é preciso discutir o conceito de revolução à luz da realidade brasileira, de tudo que, por aqui, já foi chamado de revolução. É preciso discutir conceitos como democracia, de modo que o aluno possa, por exemplo, entender o que significou a democracia na Grécia Antiga e o que significa a democracia nos diferentes momentos da história brasileira.

Em todos os casos, a ênfase é na formação cidadã. E não há formação cidadã se, objetivamente, o aluno não participar do processo. É preciso ouvir e levar a sério o que ele diz, mesmo quando o seu discurso se opõe aos valores que defendemos. Não podemos falar de escravidão colonial sem, demonstrando as especificidades de cada tema, inclusive as diferenças temporais, falar da escravidão contemporânea; e não podemos falar de escravidão contemporânea sem ouvir os alunos sobre as suas experiências trabalhistas, sobre como se organiza o seu mundo do trabalho, mesmo quando, ouvindo sobre situação de trabalho escravo, não se possa fazer nada - como no caso de um aluno submetido a jornada exaustiva e condições degradantes de trabalho, que declarou preferir isso a ficar com fome, porque outra opção não tinha.

No momento, essa comunicação terá chegado ao seu objetivo se ficar demonstrada a importância desses temas como objeto de estudo. Se ficar demonstrado que o sistema oficial no Pará, mas não só aqui, tem tornado o aluno alienígena no processo de ensino, e que é preciso, por iniciativa dos professores, inteligência e vontade para mudar isso. A realidade tornada conteúdo das aulas de história é possibilidade de caracterizar o espaço da sala de aula como lugar de significação do presente. O passado deixa de ser mera cognição, 
desbotada e sem sentido, para ser atribuição de sentido à temporalidade, cheiro e cor do mundo vivido. Essa é a educação histórica que precisa ser comutada com o ensino de história ainda majoritário no Brasil. A aula pode ter vida e cor, e educar pode ser sinônimo de emancipação humana.

A questão agrária ainda é a força que define o destino do Brasil, ainda é o grande problema brasileiro, mas, infelizmente, não é o único. O silêncio sobre a questão agrária, como o silêncio sobre as temáticas que remetem à história do povo sofrido, não é apenas uma forma de manter o povo na grande noite da ignorância, é também uma estratégia de luta na guerra dos que têm contra os que nada, ou quase nada, têm. A ignorância, ao mesmo tempo que é produto da ignorância, tem nela sua condição de existência. Embeber o povo com a beleza da história europeia, ou com a epopeia da aventura bandeirante, não é uma prática despretensiosa. Ignorar o que o povo é, em sua experiência histórica, é também privá-lo das causas dos sofrimentos e das possibilidades de luta.

\section{REFERÊNCIAS}

AFONSO, José Batista G. O massacre de Eldorado dos Carajás e a luta do movimento camponês pela terra no Sul e Sudeste do Pará. 2016. Dissertação (Mestrado em História) - Universidade Federal do Sul e Sudeste do Pará (Unifesspa). Marabá, 2016.

ALDIGHIERI, Mário. Josimo: a terra, a vida. São Paulo: Loyola, 1993.

ALVES, Márcio Moreira. A Igreja e a política no Brasil. São Paulo: Brasiliense, 1979.

BAROM, Wilian Carlos C. A teoria da história de Jörn Rüsen no Brasil e seus principais comentadores. Revista História Hoje, v. 4, n. 8, p. 223-246, 2015.

BLOCH, Marc. Apologia da História, ou ofício do historiador. Rio de Janeiro: Jorge Zahar, 2001.

CHARTIER, Roger. A história cultural: entre práticas e representações. Lisboa: Difel, 1990.

CHAVES, Patrícia Rocha. Rebeldia e barbárie: conflitos socioterritoriais na região do Bico do Papagaio. 2015. Tese (Doutorado em História) - PPGGH, Universidade de São Paulo (USP). São Paulo, 2015.

COMISSÃO PASTORAL DA TERRA (CPT). Padre Josimo: a velha violência da Nova República. Goiânia: Ícone, 1996. (Coleção Fé e Política).

DREIFUSS, René Armand. 1964: a conquista do Estado - ação política, poder e golpe de classes. Petrópolis: Vozes, 1981. 
FIGUEIRA, Ricardo Rezende. A justiça do lobo: posseiros e padres do Araguaia. Petrópolis: Vozes, 1986.

FRANCO, Maria Laura P. B. O Livro Didático de história no Brasil: a versão fabricada. São Paulo: Global, 1982.

FREIRE, Paulo. Educação como prática da liberdade. 15. ed. São Paulo: Paz e Terra, 1983.

FREIRE, Paulo. Pedagogia da autonomia: saberes necessários à prática educativa. 25. ed. São Paulo: Paz e Terra, 1996.

GUILHERME, Alexandre Anselmo; PICOLI, Bruno Antônio. Escola sem Partido: elementos totalitários em uma democracia moderna: uma reflexão a partir de Arendt. Revista Brasileira de Educação, v. 23, e230042, 2018. Disponível em: http://www.scielo.br/pdf/rbedu/v23/1809-449X-rbedu-23-e230042.pdf. Acesso em: 28 ago. 2019.

HELLER, Agnes. Uma teoria da História. Rio de Janeiro: Civilização Brasileira, 1993.

LE BRETON, Binka. Todos sabiam: a morte anunciada do Padre Josimo. Trad. Maysa Monte de Assis. São Paulo: Loyola, 2000.

MARTINS, Estevão de Rezende; SCHMIDT, Maria Auxiliadora (org.). Jörn Rüsen e o ensino de história. Curitiba: Ed. UFPR, 2011.

MARTINS, José de Souza. Os camponeses e a política no Brasil: as lutas sociais no campo e seu lugar no processo político. 2. ed. Petrópolis: Vozes, 1983.

MARTINS, José de Souza. Expropriação e violência: a questão política no campo. 3. ed. revista e aumentada. São Paulo: Hucitec, 1991.

MARTINS, José de Souza. A militarização da questão agrária no Brasil: terra e poder - o problema da terra na crise política. Petrópolis: Vozes, 1984.

PEIXOTO, Rodrigo C. D. Memória social da Guerrilha do Araguaia e da guerra que veio depois. Boletim do Museu Paraense Emílio Goeldi, Belém, v. 6, n. 3, p. 479-499, set./dez. 2011.

PEREIRA, Liliana Patrícia L. S. Os conflitos pela terra na região do Bico do Papagaio Tocantins na década de 1980. 1990. Dissertação (Mestrado em História) Universidade Federal de Goiás (UFG). Goiânia, 1990.

RÜSEN, Jörn. Didática da História: passado, presente e perspectivas a partir do caso alemão. Trad. Marcos Roberto Kisnick. Práxis Educativa, Ponta Grossa, v. 1, n. 2, p. 7-16, jul./dez. 2006.

RÜSEN, Jörn. Teoria da história: uma teoria da história como ciência. Trad. Estevão C. de Rezende Martins. Curitiba: Ed. UFPR, 2015.

SCHMIDT, Maria Auxiliadora; GARCIA, Tânia Maria F. B. A formação da consciência histórica de alunos e professores e o cotidiano em aulas de história. Cadernos Cedes, Campinas, v. 25, n. 67, p. 297-308, set./dez. 2005. 
SCHMIDT, Maria Auxiliadora; GARCIA, Tânia Maria F. B. Construindo a sala de aula como espaço de conhecimento compartilhado: cultura e ensino de história. In: CONGRESSO INTERNACIONAL DESENVOLVIMENTO HUMANO: ABORDAGENS HISTÓRICO-CULTURAIS, 1999. Caderno de Resumos. São Paulo: Universidade São Marcos, 1999.

SILVA, Ana Célia da. A representação social do negro no Livro Didático: o que mudou? por que mudou? Salvador: EDUFBA, 2011.

SILVA, Moisés Pereira. Padre Josimo Moraes Tavares e a atuação da Comissão Pastoral da Terra (CPT) nos conflitos agrários do Araguaia-Tocantins (1970-1986). 2011. Dissertação (Mestrado em História) - Universidade Federal de Goiás (UFG). Goiânia, 2011.

SILVA, Moisés Pereira. O trabalho escravo contemporâneo e a atuação da CPT no campo (1970-1995). 2016. Tese (Doutorado em História) - Pontifícia Universidade Católica de São Paulo (PUC-SP). São Paulo, 2016.

TAVARES, Josimo Moraes. Servo solidário do direito e da justiça. Goiânia: CNBB, 1999.

\section{Fontes}

BRASIL. CÂMARA DOS DEPUTADOS. Projeto de Lei n. 867/2015. Brasília: Câmara dos Deputados. Disponível em: http://www.epsjv.fiocruz.br/sites/default/files/files/PL.pdf. Acesso em: 28 ago. 2019.

BRASIL. SENADO FEDERAL. Projeto de Lei n. 193/2016. Disponível em: https://www25. senado.leg.br/web/atividade/materias/-/materia/125666. Acesso em: 15 maio 2017.

\section{Entrevista}

ROZIERS, Henri Burin des. Henri Burin des Roziers: depoimento [fev. 2010]. Entrevistador: Moisés Pereira da Silva. Xingura, 13 fev. 2010. 2 arquivos de áudio. Entrevista realizada em pesquisa de mestrado.

\section{NOTAS}

${ }^{1}$ Em 24 de maio de 2017 a polícia, numa ação planejada segundo o Ministério Público do Estado do Pará, assassinou 10 trabalhadores rurais sem terra acampados na Fazenda Santa Lúcia, município de Pau D’arco, sudeste do Pará, episódio que ficou conhecido como Massacre de Pau D’arco.

${ }^{2}$ Nas unidades de medidas agrárias um hectare corresponde a $10.000 \mathrm{~m}^{2}$. No sul do Pará um alqueire de terra é igual a 2,72 hectares, ou $27.200 \mathrm{~m}^{2}$ de terra.

${ }^{3}$ As primeiras correntes migratórias significativas para a Amazônia ocorreram entre o final do século XIX e o início do século XX, sob a influência da economia da borracha e 
incentivadas por falsas propagandas do governo federal. Tratou-se de um grande engodo, posto que, sobretudo o migrante nordestino, viu-se enredado pela escravidão na Amazônia sob a forma do sistema de aviamento. A segunda onda migratória, em parte novamente incentivada pelo governo, deu-se entre o final da década de 1960 e os anos 1970, quando camponeses expulsos de suas terras acreditaram na possibilidade de encontrar terras para, pelo trabalho, reproduzir a vida com alguma dignidade na Amazônia.

${ }^{4}$ Expressão muito comum nos garimpos da Amazônia para traduzir a boa sorte daqueles que encontram metal precioso em quantidade que os deixa ricos.

${ }^{5}$ José de Souza Martins (1984) avalia que à expectativa camponesa, e consequente mobilização, em torno do projeto de reforma agrária correspondeu, com forma muito maior, o recrudescimento da repressão reclamada pelo capital, o que acontecia, como indica Peixoto (2011) sob o discurso que reinventava a Guerrilha do Araguaia.

${ }^{6}$ Textos de autoria do padre Josimo organizados e publicados pela Conferência Nacional dos Bispos do Brasil em 1999, por ocasião do $13^{\circ}$ ano da sua morte.

${ }^{7}$ Textos particulares são as correspondências, das quais se teve acesso apenas às que enviou à dona Olinda, sua mãe, e a dom Cornélio Chizzini, seu bispo. Textos públicos são os muitos escritos, de variados estilos, que, embora sem destinatário, quase sempre se dirigiam aos camponeses, entre os quais seus paroquianos em Wanderlândia e, depois, em São Sebastião.

${ }^{8}$ A maioria dos relatórios de violência no campo sobre o Bico do Papagaio era produzida por Josimo e sua equipe, embora os denunciantes finais fossem bispos ou outras autoridades ligadas à Comissão Pastoral da Terra (CPT).

${ }^{9}$ O projeto de Lei $n^{\circ} 867 / 2015$ que tramitou na Câmara Federal e o Projeto de Lei no 193/2016, que tramitou no Senado constituem síntese dos esforços de um grupo significativo político, econômico e social que pretende, alternativo à "educação como ato político", nos dizeres de Freire (1983; 1996), e à "consciência histórica", na acepção de Rüsen (2006; 2015), impor um modelo de ensino e de aprendizagem acríticos, fundados no que Picoli e Guilherme (2015) identificam como elementos de uma proposta totalitária.

${ }^{10}$ A Comissão Pastoral da Terra criou um espaço na internet (https://www.cptnacional.org. $\mathrm{br} / \mathrm{mnc} /$ ) com informações importantes sobre os massacres no campo. Nesse endereço é possível acessar os dados, distribuídos por ano, da violência agrária no Brasil. A dissertação de José Batista Gonçalves Afonso (2016), advogado da CPT, também é leitura importante para quem deseje compreender a dinâmica das relações que engendram violências como os Massacres de Eldorado e de Pau D’Arco. Outra leitura imprescindível sobre a violência no Araguaia é o estudo de Rodrigo Corrêa Diniz Peixoto (2011).

Artigo recebido em 20 de março de 2019. Aprovado em 20 de novembro de 2019. 